\title{
Benefits of the Inclusion of Occupant Behaviour Profiles in the Simulation of the Energy Performance of Buildings
}

\author{
Davide Calì $^{1}$, Dirk Müller ${ }^{2}$, Henrik Madsen ${ }^{1,3}$ \\ ${ }^{1}$ Technical University of Denmark (DTU), Lyngby, Denmark \\ ${ }^{2}$ EBC, E.ON Energy Research Center, RWTH Aachen University, Germany \\ ${ }^{3}$ Norwegian University of Science and Technology (ZEN-project), Trondheim, Norway
}

\begin{abstract}
Within the simulation of buildings' energy performance, Occupant Behavior is often modelled only through fixed and repeated profiles. The incorrect simulation of occupant behavior can however lead to the so called Energy Performance Gap both in new and retrofitted buildings. In this work, we demonstrate how integrating real occupants' profiles related to the opening and closing of windows can positively affect the results of the dynamic performance simulation of buildings. Within this scope, we modelled (Dymola, Modelica) two 10-apartments buildings and their HVAC systems, and simulated those under two main scenarios, one with a fixed air change rate through windows, one including opening and closing cycles as monitored in the real building. Including realistic windows' ventilation can improve the simulation results, but a holistic occupant behavior is highly necessary to get reliable and accurate buildings' simulations.
\end{abstract}

\section{Introduction}

The energy performance gap (EPG) of buildings (Galvin, 2014) is a well-known phenomenon and affects both new (Menezes et al., 2012; Dall'O' et al., 2012) and retrofitted buildings (Haas and Biermayr, 2000; Tronchin and Fabbri, 2008). Those buildings are often less performing than predicted, while old buildings, in contrast, use often less energy than expected. Dynamic building models are often used to predict the energy performance of buildings more accurately than static energy balance procedures (e.g. procedures described in guidelines and standards, to produce energy labels). However, such dynamic models are often simulated using standard occupants' profiles: the set temperature of rooms, the air change rate through windows, the heat gains and the sun blinds are often set to constant values, or varies following a given profile. Beside the advantage of better predictions of the energy performance of buildings, accurate occupants models could be integrated in model predictive control systems of buildings to optimise HVAC operations and hence reduce energy use and $\mathrm{CO} 2$ emissions of buildings, or could be implemented to test the interaction of one or more buildings with the energy grids in grid simulations (Molitor et al., 2012), or for the purpose of testing hardware (Molitor et al., 2012) or software in the loop (Moli- tor et al., 2011). For those reasons, in recent years, the scientific community is striving for implementing consistent and robust occupant behaviour models into the simulation of the buildings' energy performance (e.g. within the IEA Annex 66 and Annex 79).

Including proper models of occupant behavior (OB) in buildings is connected to a high modelling and simulation effort, and the scientific community does not yet have a holistic model to simulate OB. Effort has been spent in understanding modelling the OB especially related to natural ventilation, and Fabi et al. (2012) offer a optimal literature review on this topic and put the basis for future development of OB models. In this work, we investigate how the inclusion of real opening and closing cycles of windows within a building energy performance simulation influences the simulated energy performance, and hence try to answer the questions:

- Can the inclusion of observed opening and closing window cycles in building energy performance simulation lead to better predictions of the energy use in buildings?

- Can the only inclusion of opening and closing cycles of windows be enough to get accurate buildings' energy performance predictions?

To tackle those research questions, we selected two buildings (with different ventilation systems) from a field test of nine buildings, described in details in Calì et al., 2011a,b. We searched for models able to simulate the air change through open windows, and hence tested and implemented three different models and selected the most suitable model. Moreover, we simulated two main simulation scenarios and compared those to the real energy use of the buildings. In a scenario no. one, the air change rate of the buildings is constant, while scenario no. two, this varies depending on the observed windows' state (open/closed) and the average opening angle of windows (we selected three average opening angles, $6^{\circ}, 8^{\circ}, 10^{\circ}$ ). Models and results of this paper are based on (Calì, 2016).

\section{Models of the buildings and the HVAC}

We modelled and simulated two buildings using the simulation environment Dymola and the modeling language Modelica. The models of the HVAC systems and of the building components are based on the libraries developed at the RWTH Aachen University (Fuchs et al., 2015). 
Figure 1: Schematic overview of the buildings' model as presented in Cali (2016).

The main simulation model illustrated in figure 1 , comprehends:

- a weather model,

- a building model, that includes the building's envelope (outer walls, windows) and the inner walls, doors, and furniture,

- a model of the heating system, including generation, storage, distribution and delivery of the heating energy,

- a model of the ventilation system, consisting of a module for natural ventilation and air infiltration, and a module for mechanical ventilation and a module for air infiltration,

- and an occupants' model, to allow for the input of occupants presence and behavior profiles (in this case the opening and closing patterns of windows).

\section{Description of the buildings}

We selected 2 buildings out of a field test consist of three big building blocks, each offering 3 entrances to three buildings, with a total of 30 apartment per building block (10 apartments per building) over five floors (figure 2). Each apartment has a size of $72 \mathrm{~m}^{2}$ of nominal floor surface (NFS, calculated based on the German Standards following the EnEV procedure (Deutsches Institut für Normung e.V., 2014)). The buildings were built at the end of the fifties and were retrofitted between 2009 and 2011. For the purpose of this study, we selected building B2E3 (located in building block 2) and building B3E1 (located in building block 3).

B2E3 $16 \mathrm{~cm}$ insulation with $\lambda=0.021 \mathrm{~W} /(\mathrm{mK})$ on the facade and on the floor of the pitched roof and $8 \mathrm{~cm}$ insulation with $\lambda=0.024 \mathrm{~W} /(\mathrm{mK})$ on the basement ceiling. B2E3 has double glazed windows with an $\mathrm{U}$-Value of $1.3 \mathrm{~W} /(\mathrm{mK})$. The windows are equipped with sun-blinds and daylight guidance system. B3E1 has $4 \mathrm{~cm}$ insulation with $\lambda=0.021$ $\mathrm{W} /(\mathrm{mK})$ and $4 \mathrm{~cm}$ vacuum panels $\lambda=0.008 \mathrm{~W} /(\mathrm{mK})$ on the facade, with $16 \mathrm{~cm}$ insulation with $\lambda=0.021$ $\mathrm{W} /(\mathrm{mK})$ on the base of the pitched roof and $8 \mathrm{~cm}$ in-

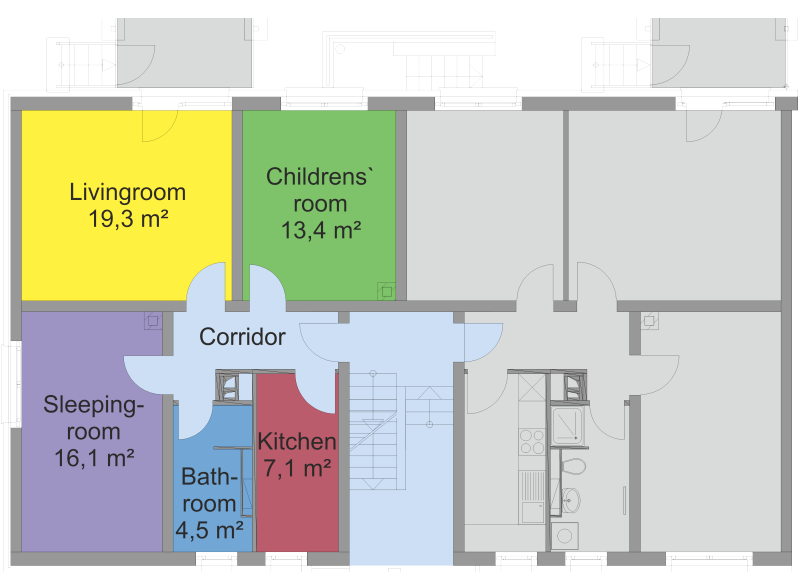

Figure 2: Floor plan of each floor (Cali, 2016).

sulation with $\lambda=0.024 \mathrm{~W} /(\mathrm{mK})$ on the basement ceiling. B3E1 is equipped with triple glazed passive house windows and an average U-Value of 0.8 $\mathrm{W} /\left(\mathrm{m}^{2} \mathrm{~K}\right)$. Also in B3E1, the windows are equipped with sun-blinds with daylight guidance systems.

B2E3 is connected to a district heating network. The heat is delivered to the rooms through floor heating panels (the bathroom also offers a towel radiator), each controlled separately in each room through a micro heating pump. B2E3 is equipped with a central exhaust air ventilation system.

B3E1 is heated through a modulated, ground source heat pump (equipped with $\mathrm{CO}_{2}$ heat probes). As for $\mathrm{B} 2 \mathrm{E} 3$, also in B3E1 the heat is delivered to the rooms through floor heating panels (the bathroom also offers a towel radiator), each controlled separately in each room through a micro heating pump. In B3E1, each apartment has an own ventilation system: This recovers the heat from the exhaust air that was extracted from the bathroom and the kitchen, and supply this heat to the supply air to the sleeping, the living and the children's rooms. During standard operation mode, the ventilation system supply $70 \mathrm{~m}^{3} / \mathrm{h}$ of air and has a heat recovery factor up to $\eta_{\mathrm{HR}}=90 \%$. B2E3 is designed to use $45 \mathrm{kWh} /\left(\mathrm{m}_{N F S}^{2} a\right)$ while B3E1 is designed to use $28 \mathrm{kWh} /\left(\mathrm{m}_{N F S}^{2} a\right)$ primary energy for heating, ventilation and DHW production (Cali, 2016). The rooms have been monitored in terms of $\mathrm{CO}_{2}$, VOC, temperature, humidity, illuminance, window state (open/closed) and light source with a timestamp of one minute, for over 4 years (2010-2014), while the energy flows for heating and DHW were also monitored at building and apartment level. Those monitoring data were used to validated the models of buildings and of the HVAC components (Wesseling, 2012).

\section{Weather model}

The weather model uses the collected data from a weather station installed in B2E3. In the model, we approximate the direct and the diffuse solar radiation, by using the observed global solar radiation from the weather station as an input; the approximation is based on the algorithm developed by Erbs et al. 
(1982)). Moreover, the weather model calculates, for each side of the building, the direct solar radiation.

\section{Model of the Building Structure}

We modelled the building structure with a modular approach. Walls, floors and ceiling are modeled based on their structure in n-layers (where "n" represents a set of layers, each with a specific material), hence considering both heat transmission and heat capacity for each single layer. Detailed windows' and doors' heat transmission models are integrated in the wall models. In addition, we added in each room a thermal mass in order to reproduce the effect of the heat capacity of the furniture.

\section{Model of the Heating System}

A floor heating model developed and validated through field test data in (Wesseling, 2012) was used for delivering the heating energy to the rooms. A PIcontroller, controlling the volume flow of the heating water into the radiant surfaces, ensure the set temperature in the rooms is reached, emulating the control of the installed micro heating pumps. As in the real buildings, also the simulation model has a hot water tank with a capacity of 750 l, used for the heating system. A circulation pump installed between the tank, the floor heating and the radiators is also modeled. To simulate a connection to the district heating $(\mathrm{DH})$ network, the hot water tank of B2E3 is heated through an ideal hot water source, with a fixed temperature, and a heat meter (HM) measures the energy used by the heating system (figure 3 ).

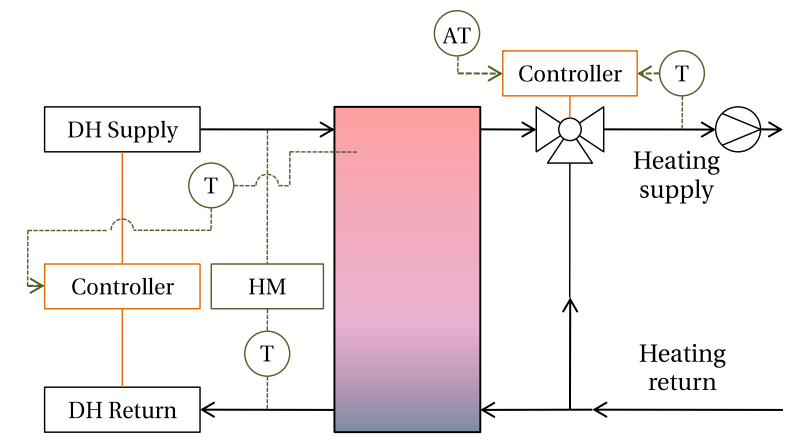

Figure 3: Model scheme of the heating system of B2E3 with a hot water tank in the center (Cali, 2016).

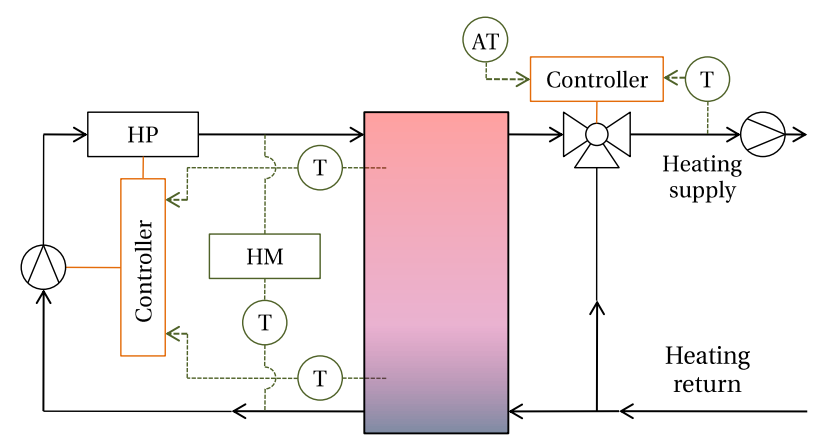

Figure 4: Model scheme of the heating system of B2E3 (Cali, 2016).

In B3E1 we modelled a modulated heat pump (HP,
Model Heliotherm HP28E-WEB), following the specifications and the characteristic curves provided by the heat pump producer. B3E1 also has a hot water storage of 7501 (figure 4); in this model, the coefficient of performance, the produced heating energy and the consumed electrical energy are calculated based on the characteristic curves provided by the HP producer, hence we take into account the dependency of the COP both on the condenser temperature and on the evaporator temperature. The heat source of this heat pump, consisting of 12 direct evaporation $\mathrm{CO}_{2}$ ground heat probes, has not been modeled: instead, the heat pump has a fixed temperature boundary on the evaporator side, set at $8^{\circ} \mathrm{C}$.

\section{Air Node Model}

The standard Modelica air node model represents a volume of ideally mixed air. We upgraded this model in order to include both the moisture in the air and the concentration of the carbon dioxide. The model of the volume of air is thermally connected to the walls and to the heat sources (floor heating for all rooms, floor heating and a radiator in the bathroom) and can be connected to moisture and carbon dioxide sources. Through apposite interfaces, the air exchange with the ventilation system, the windows, the doors and the façade (for air infiltration) is integrated in the simulation.

\section{Mechanical Ventilation System Model}

B2E3 has an exhaust air ventilation system, where the air enters the apartment through apposite window frame slots located in windows in the bedrooms, living rooms and children's rooms; then, the air flows through the corridor, before it get extracted in kitchens and bathrooms. For simplicity (we do not know the air pressure on each facade, nor the position of the doors), the air flow is considered to be ideal and to flow as planned (the doors have apposite openings for air circulation). We hence ignore changes in the air flow caused by special configurations of the state (open/close) of windows and doors. For B2E3, we consider the air constantly flowing as follows:

- from the outdoor to the living, sleeping, and children's, room respectively with $30 \mathrm{~m}^{3} / \mathrm{h}, 20$ $\mathrm{m}^{3} / \mathrm{h}$ and $20 \mathrm{~m}^{3} / \mathrm{h}$,

- then flowing from those rooms to the corridor,

- finally extracted in the kitchen and the bathroom, with $35 \mathrm{~m}^{3} / \mathrm{h}$ each room.

Each apartments in B3E1 has a heat recovery unit. We modelled this unit as an air to air heat exchanger (where the overall coefficient of heat transfer of the heat exchanger depends on the geometry of the heat exchanger and on the heat transfer coefficient $\alpha$ of each side of the heat exchanger), following the VDI "Waermetlas" (VDI, 2002). Calì (2016) offers a description of our implementation of this model. 


\section{Windows' ventilation model}

From the literature, we selected three models able to simulate the air exchange through windows without simulating the entire fluid dynamic: A model is based on the European standard DIN-EN-15242 (2007), a model based on laboratory measurements and developed by Hall (2004), a model (developed mainly for summer time ventilation) deployed by (Schnieders, 2003). A comparison of those models, motivating our choice, is provided in Calì (2016). We have chosen the model described by the European standard DINEN-15242 (2007), which offers a general approach to model the air change through the windows, for any window opening angle. The volume flow is modeled based on the geometry of the window, the wind turbulence, the wind speed and the thermal buoyant forces. There is no distinction between classic opening and tilted opening of the window.

\section{Check of the room model}

In order to check the validity of our ventilation models (the heating system model was validated in Wesseling (2012)), we simulated, under four scenarios, the model of a children room, intended as the combination of the air node and the construction elements (walls, ceiling, floor, windows and doors). We hence compared the simulated indoor temperature to the observed room temperature. The temperature of adjacent rooms is set as recorded by the monitoring system. The room is simulated together to the weather model, hence the observed weather is provided as an input. The comparison is made for May 2013 (no heating). The four simulated scenarios are described

Table 1: description of the simulated scenarios

\begin{tabular}{|c|c|c|c|}
\hline Scenario & $\begin{array}{c}\text { No. of } \\
\text { Occup. }\end{array}$ & $\begin{array}{c}\text { Window } \\
\text { vent. }\end{array}$ & $\begin{array}{c}\text { Blinds } \\
\text { automat. }\end{array}$ \\
\hline 1 & 0 & No & No \\
2 & 1 & No & Yes \\
3 & 0 & Yes & Yes \\
4 & 1 & Yes & Yes \\
\hline
\end{tabular}

in table 1 and differ in terms of presence of occupants (producing internal gain), modelling of natural ventilation and automatic use of blinds. The results of the four scenarios can be found in Calì (2016), while here we only compare scenario 1 (S1) to scenario 4 (S4). Figure 5 shows the observed and the simulated room temperature under S1, both in form of histograms and of time series: the room has no occupants, the ventilation is considered running constantly at standard values $\left(\mathrm{n}_{A C H, t o t}=0.551 / \mathrm{h}\right.$ and the shading system is off. Compared to the observed room temperature, the simulated temperature under S1 shows higher peaks (due to excessive solar gains, not avoided by the blinds) and has no temperature drops due to natural ventilation (opening of windows).

In S4 (figure 6), the room is simulated with the constant presence of one occupant; the ventilation is simulated as under $\mathrm{S} 1$ and the shading system is active
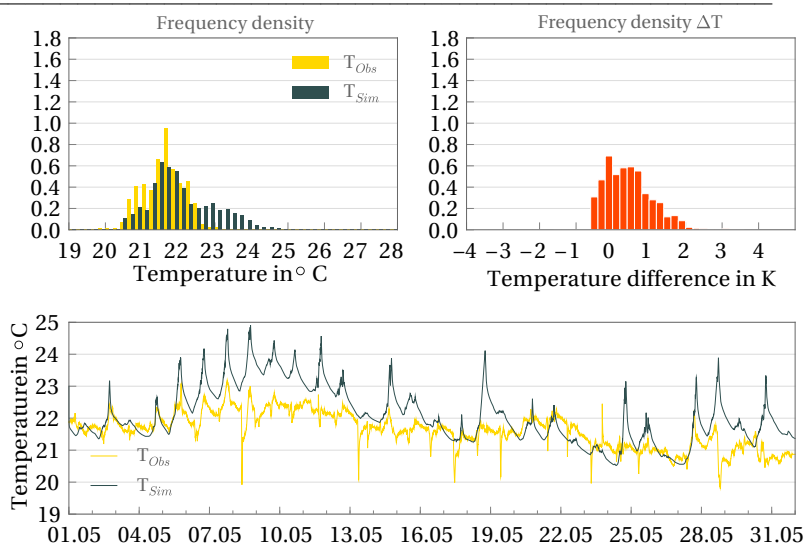

Figure 5: S1, observed vs. simulated room temperature in a children room, Cali (2016)
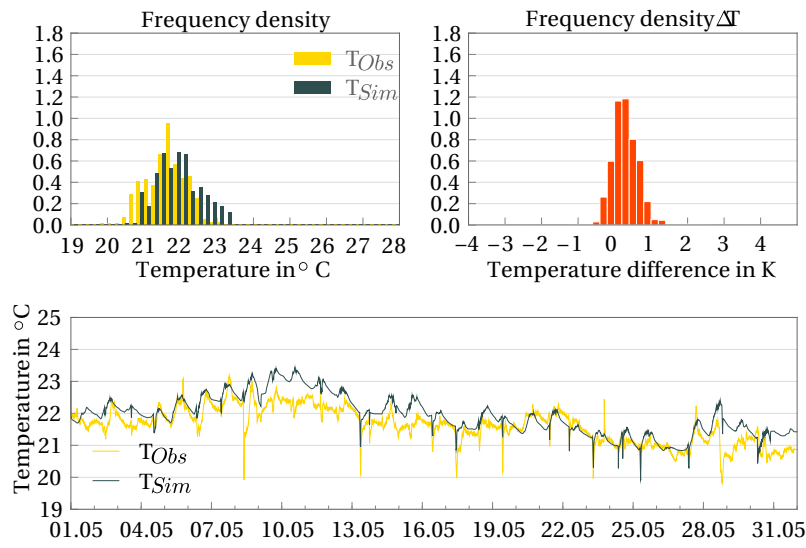

Figure 6: 54 , Observed vs. simulated room temperature in a children room, Cali (2016)

and shades the window as soon as the direct solar radiation on the window is over $500 \mathrm{~W} / \mathrm{m}^{2}$. Under $\mathrm{S} 4$, the observed and the simulated room temperature correlate better than for all other scenarios: the shape of the frequency density histograms of the observed and the simulated temperature are similar, the histogram of the frequency density of the temperature difference (simulated - observed temperature) is narrow and almost centered, the temperature profiles are similar.

Looking at the temperature profiles in figure 6 , we can see how some days the model fits the reality, while in other days the simulated temperature is over $1 \mathrm{~K}$ higher than the real temperature. A comparison between S3 and S4 (Calì, 2016) demonstrates how sensitive the model is to the presence of one occupant (and hence to the heat this occupant generates: however, no information about the real occupancy of the apartments is available. Also, the use of the blinding system plays strongly affects the room temperature, as verified by comparing the results of S1 and S2 (Calì, 2016). However, also information about how the occupants interacted with the blinding is not available.

\section{Energy Performance Simulation}

The simulations results illustrated in this work are obtained under the following settings: 
- The rooms set temperature is set to $20^{\circ} \mathrm{C}$;

- Shading system: off;

Further, we used the following boundaries:

- The cellar temperature is set to $16^{\circ} \mathrm{C}$;

- The stairs temperature is set to $18^{\circ} \mathrm{C}$;

- The temperature of the ground, used ad heat source of the heat pump, is constantly set to $8^{\circ} \mathrm{C}$;

- The temperature of the apartments in the neighboring entrance is set to $22^{\circ} \mathrm{C}$;

- Constant internal gains set to $5 \mathrm{~W} / \mathrm{m}^{2}$ as recommended in the DIN standard 4108-6;

- Wind direction is not considered (the wind has the same speed on each side of the building);

- In each room, the furniture is modeled as a $100 \mathrm{~kg}$ mass of wood.

The two buildings were simulated under real weather conditions in the heating period between 2012 and 2013 (we refer here to the heating period, as the period between January and April, and between October and December). The buildings were simulated under two main scenarios:

1. Scenario 1 (S1): Ventilation through constant air change rate $\left(n_{\mathrm{ACH}, \text { tot }} 0.551 / \mathrm{h}\right.$ for $\mathrm{B} 2 \mathrm{E} 3, n_{\mathrm{ACH} \text {,tot }}$ $0.61 / \mathrm{h}$ for B3E1. Those values are based on the DIN standard 4108-06 and include both natural and mechanical ventilation).

2. Scenario 2 (S2): Constant mechanical ventilation $\left(n_{\mathrm{ACH}, \text { mech }} 0.41 / \mathrm{h}\right.$ for B2E3 as implemented in the real buildings, $n_{\mathrm{ACH} \text {,mech }} 0.31 / \mathrm{h}$ for B3E1 (however, in real buildings occupants can still switch off the ventilation system, or switch it on in standard $(0.3 \mathrm{ACH})$ and max $(0.6 \mathrm{ACH})$ mode), variable air infiltration, real window state profiles for natural ventilation.

Since the real opening angle of the windows was not monitored, and Windows in tilted state have an opening angle between 3 and 5 (Fritzner, Klaus, Finke, Ulrich, 2012), we simulated 3 sub-scenarios with different opening angles, to simply represent possible combinations of tilted and completely open windows:

- Scenario S2.A $\beta=6^{\circ}$,

- Scenario S2.B $\beta=8^{\circ}$,

- Scenario S2.C $\beta=10^{\circ}$.

Figure 7 provides an extract of the key monitoring data of the buildings. For B2E3 only for 60 windows' panels the state was correctly registered, out of the 70 monitored window panels (children rooms and sleeping rooms have each two independent opening panels plus a third secondary panel, that can only be opened when the first panel is open; the secondary panel was not monitored). For the remaining 10 window panels, no information is available. For B3E1, the position of 67 window panels is known. Within the simulation, the window panels for which the position is unknown, are simulated as closed; as a consequence, the overall average time with windows open is artificially reduced. Figure 7 shows the average time with windows open, is calculated based only on the window panels for which the data is available.

\begin{tabular}{|cc|c|c|c|c|c|c|c|}
\cline { 2 - 8 } & & \multicolumn{2}{|c|}{$\begin{array}{c}\text { Mean indoor temp. } \\
\text { in }{ }^{\circ} \mathrm{C}\end{array}$} & \multicolumn{2}{|c|}{ Mean time with Windows Open } & \multicolumn{2}{c|}{$\begin{array}{c}\text { No. of Windows } \\
\text { with sensor failure }\end{array}$} \\
\cline { 2 - 9 } & $\begin{array}{c}\text { Entire } \\
\text { year }\end{array}$ & $\begin{array}{c}\text { Heating } \\
\text { period }\end{array}$ & Entire year & Heating period & $\begin{array}{c}\text { Heating period } \\
\text { incl. sensor } \\
\text { failures }\end{array}$ & Abs. & Rel. \\
\hline B2E3 & 2012 & 22.4 & 21.5 & $26.9 \%$ & $9.0 \%$ & $7.7 \%$ & 10 & $14 \%$ \\
\hline \multirow{2}{*}{ B3E1 } & 2013 & 22.3 & 21.6 & $24.6 \%$ & $7.5 \%$ & $6.4 \%$ & & \\
& 2013 & 23.5 & 22.6 & $29.7 \%$ & $9.9 \%$ & $9.4 \%$ & 3 & $4 \%$ \\
\hline
\end{tabular}

Figure 7: Observed average indoor temperature, average time of windows in open state, number of windows with sensor failure (no data available), Cali (2016).

\section{Heating energy use of the buildings}

We compare here the simulated heating energy use of B2E3 and B3E1, for all scenarios, to the observedone.

Figure 8 shows the observed and the simulated heating energy use for B2E3 in the year 2012 (up) and 2013 (buttom). The simulation scenario with natural ventilation leads to more realistic results than the scenario with a constant air change rate for both simulated years. In particular, S2.B can best reproduce the real energy use observed in 2012, while S2.C can best reproduce the energy use in 2013. Moreover, depending on the month, S2.A, S2.B or S2.C may better reproduce the real energy use. This can be explained by changes in behavior of the occupants, e.g. related to different window opening angles (tilted, completely open) depending upon the outdoor temperature, different use of the shading system and different settings for the heating system, as explained in Calì (2016).

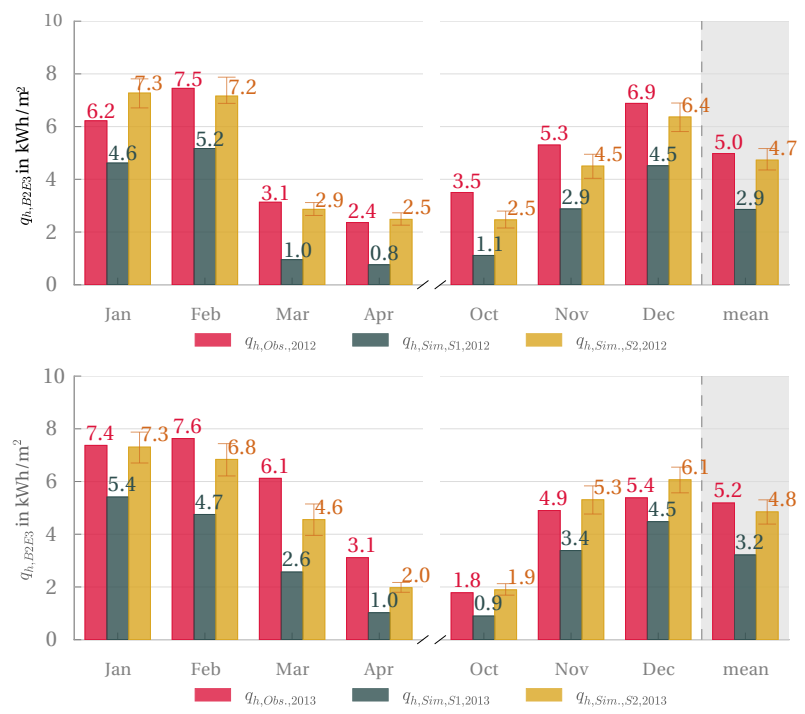

Figure 8: B2E3: Observed energy use (red), simulated energy use under $S 1$ (grey), simulated energy use under S2: The golden bars represents S2.B $\left(\beta=8^{\circ}\right)$, the error bars the results of S2.A $\left(\beta=6^{\circ}\right.$, lower error bar) and S2.C $\left(\beta=10^{\circ}\right.$, upper error bar), Cali (2016)

The observed and the simulated heating energy use for B3E1 in the year 2012 and 2013 are shown in Figure 9. In this case, the results are ambiguous. B3E1 


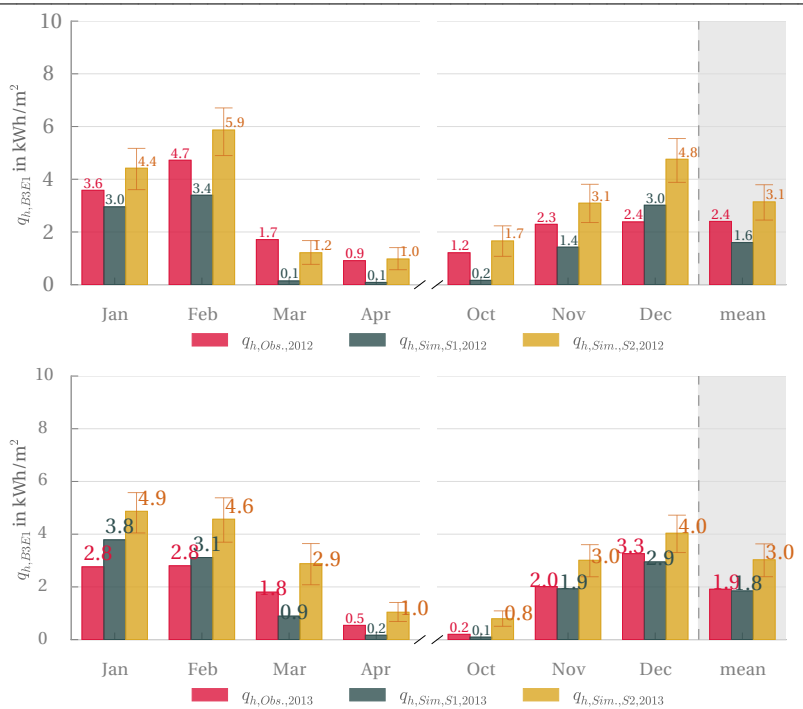

Figure 9: B3E1, same legend as figure 8, source: Cali (2016)

reduces by over $20 \%$ the monthly average energy use from $2.4 \mathrm{kWh} /\left(\mathrm{m}^{2} \mathrm{M}\right)$ to only $1.9 \mathrm{kWh} /\left(\mathrm{m}^{2} \mathrm{M}\right)$, even if the heating period 2013 was colder than the heating period 2012. We can explain this change partly by a change in behavior regarding the natural ventilation. The time with opened windows changes for B3E1 from $9.9 \%$ to $7.7 \%$, as shown in figure 7 . However, during the heating period, the observed average indoor temperature is $0.3 \mathrm{~K}$ higher in 2013 than in 2012. Due to the weather conditions, scenario S1 predicts higher energy use for 2013 than for 2012, while, the inclusion of the observed windows opening cycles in scenario S2 mitigates this effect and correctly predicts a lower energy use for 2013 compared to 2012, as for the real, observed energy use.

During December 2012, January and February 2013, none of the scenarios is able to reproduce the observed heating energy use for B3E1. All in all, for 2012, scenario S2.A best reproduces the observed heating energy use. On one hand, for the heating period 2013, scenario $\mathrm{S} 1$ has the smallest average error referred to the observed heating energy use. On the other hand, if we exclude the first two months of 2013, Scenario S2.A again best follows the seasonal changes of the observed energy use.

Considering both heating periods, S2.A can better reproduce the observed heating energy use for B3E1: the observed average monthly heating energy use is in fact equal to $2.2 \mathrm{kWh} /\left(\mathrm{m}^{2} \mathrm{M}\right)$, the simulated energy use under $\mathrm{S} 1$ is equal to $1.7 \mathrm{kWh} /\left(\mathrm{m}^{2} \mathrm{M}\right)$, under $\mathrm{S} 2 . \mathrm{A}$ is equal to $2.4 \mathrm{kWh} /\left(\mathrm{m}^{2} \mathrm{M}\right)$.

Moreover, while for B2E3 a larger window opening angle ( $8^{\circ}$ for 2012 and $10^{\circ}$ for 2013 ) provides the best prediction of the energy use, for B3E $16^{\circ}$ is the most realistic opening angle (and most likely $5^{\circ}$ would be more appropriate to simulate B3E1 in 2013): the difference could derive by different $\mathrm{OB}$, especially in respect to the use of windows. However, the bigger opening angle for B2E3 under S2 is probably mostly due to the fact that the data of 10 windows pan- els was missing (while only 3 panels are missing for B3E1), and those windows were therefore (unrealistically) considered as closed. Therefore, the higher window opening angle probably compensates this underestimation of windows in open state.

Regarding the total energy use in buildings, the integration of a simple natural ventilation model for window opening cycles can lead to more realistic predictions of the heating energy use of buildings within a building energy performance simulation. However, the average window opening angle can have a huge impact on the simulation results. Hence, this aspect should be further analyzed in future demonstration studies, where the opening angle of windows could be monitored.

\section{Heating energy use at apartment level}

The integration of the occupants' behavior in dynamic building simulations can help differentiating occupants impact on the energy performance of single dwellings. We therefore compare here the observed and the simulated heating energy use of the single apartments.

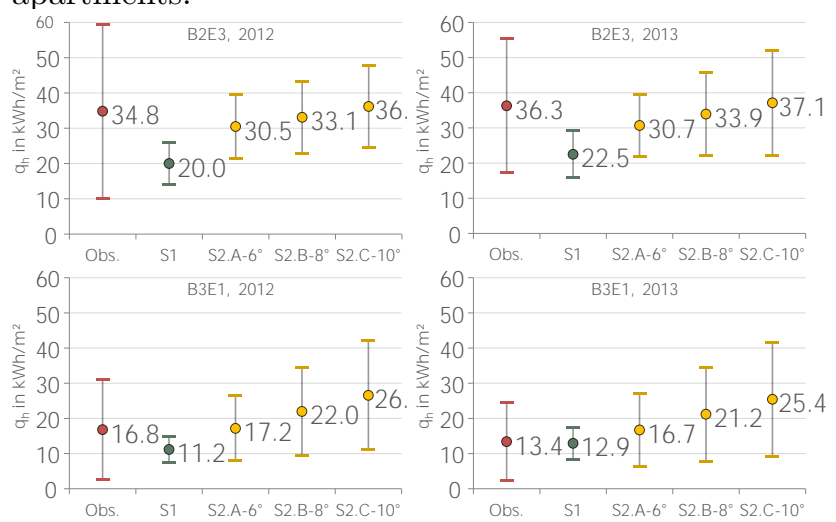

Figure 10: Energy use and related standard deviation for the apartments of B2E3 (top) and B3E1 (bottom) during 2012 (left) and 2013 (right), Cali (2016).

Figure 10 shows the average heating energy use during 2012 and 2013, and the related standard deviation, for the apartments located in B2E3 and B3E1. Under S1, the differences in the heating energy use values among the apartments are due to the location of the apartments in the buildings. Five apartments of B2E3 have a North orientation of the gable. The differences among apartments are smaller in B3E1, where the gable is oriented to the south, and the window of each sleeping room (of these gable apartments), is South oriented (for the other apartments the windows in sleeping rooms are East oriented): hence, the apartments on the gable have more transmission surface to the outside compared to the other apartments; but, however, these apartments receive greater solar gains through the windows in the sleeping rooms).

The differences between heating energy use among the dwellings are clearly bigger for S2 than for S1: On one hand, through the implementation of real windows' opening cycles, we can hence successfully 
integrate the occupants' behavior into the simulation results. On the other hand, a comparison of the observed and the simulated heating energy use, apartment-wise, demonstrates how the profile of windows alone cannot guarantee a perfect representation of the energy use of each apartment. The heating energy use values of each apartment of B3E1 during 2012 are, as an example, visualised in figure 11. While S2.A can more realistically reproduce the observed heating energy use than scenario $\mathrm{S} 1$ for 6 apartments (A1, A2, A6, A7, A9, A10), for four apartments (A3, A4, A5, A8) we can observe an opposite situation. Interestingly, apartment A4 was not heated during the entire heating period, but under scenario S2.A, the heating energy use of this apartment is almost 3 times greater than under scenario S1: probably, the apartment has high internal gains, the occupants keep windows open for a relatively long time, and do not use the heating system. In contrast, apartment A3 is heated more under S1 than S2.A, but the observed energy use is even higher than the simulated one. Probably, in this apartments the occupants ventilate the rooms with completely open windows for short time periods (a higher opening angle of the windows would

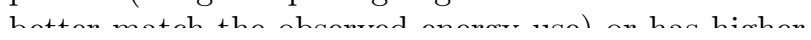

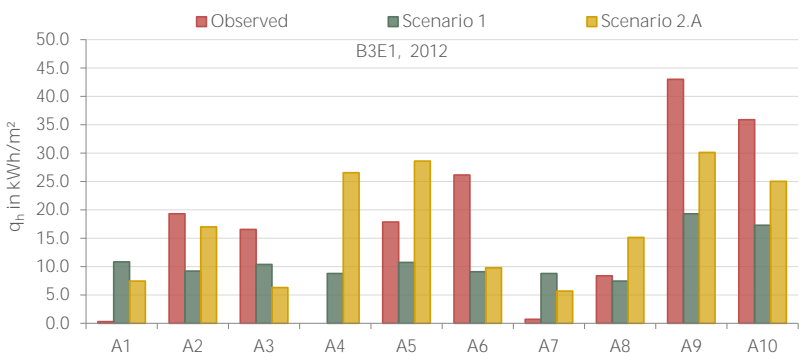

Figure 11: Observed and simulated heating energy use of the apartments in B3E1 in 2012 (Cali, 2016).

In Calì (2016) and Calì et al. (2016) we illustrated that, besides the different behavior regarding natural ventilation, occupants also heat their apartments differently. Occupants have different presence profiles, different thermal comfort demands and different approaches when using sun blinds. This results into a high spread of heating energy use: Many apartments are heated by less than $5 \mathrm{kWh} /\left(\mathrm{m}^{2} \mathrm{a}\right)$, other apartments require over $60 \mathrm{kWh} /\left(\mathrm{m}^{2} \mathrm{a}\right)$. We also showed in Calì et al. (2016) how some of the apartments get enough heating energy from the neighbors and do almost not require any further heating energy (and still have windows open for a long time). For this reasons, only a holistic approach allows to model the combination of the different aspects of occupant behavior, and hence realistically predict the energy use of each individual dwelling. An occupants' model for natural window ventilation, is therefore only one step towards the modeling of the occupant behavior as a whole.

\section{Conclusion}

Natural ventilation models can lead to two main benefits when simulating the dynamic performance of buildings: better predictions of the energy use, and a diversity in the energy use among identical apartments. However, as expected, the prediction is still relatively imprecise, when focusing on individual apartments. Yet, occupants affect the indoor environment and also the performances of the buildings through their own presence, the production of internal gains, the temperature settings, the settings of the ventilation system and the use of sun blinds. Hence, the differences between simulated and observed energy use at apartment level are not surprising.

Particularly relevant is how the occupants' simultaneous interactions with sun blinds, settings of the HVAC system and windows can generate issues, when the real behavior of window opening is simulated but the other activity ignored. In some cases, occupants might leave the windows open over a long period while keeping the heating switched off: hence, the simulation still strives to achieve the standard set temperature of $20^{\circ} \mathrm{C}$, generating an unrealistically high heating energy use.

In conclusion, including an occupant behavior model related to the natural ventilation habits of occupants is a valuable step in the generation of more realistic simulation models of buildings; However, a holistic approach to simulate the behavior of occupants should be preferred. In Calì et al. (2018) a method to generate realistic window state profiles, based on the Markov chain technique and making use of the monitored data from this field test, is proposed, evaluated and discussed. When occupancy profiles are known, logistic regression models (Calì et al., 2016) or mixed effect models (Haldi et al., 2017) could be used to simulate the human interaction with windows.

\section{Acknowledgment}

We gratefully acknowledge the financial support of BMWi (03ET1105A, 03ET1289D), the European Union, through Interreg Öresund-Kattegat-Skagerrak (NYPS 20200999), European Regional Development Fond, grant 'Smart Cities Accelerator', the Volkswohnung and E.ON New Build and Technology.

\section{References}

Calì, D. (2016). Occupants' Behavior and its Impact upon the Energy Performance of Buildings. Dissertation, RWTH AACHEN UNIVERSITY, Aachen, Germany. https://publications.rwth-aachen. de/record/677868/files/677868.pdf.

Calì, D., R. K. Andersen, D. Müller, and B. W. Olesen (2016). Analysis of occupants' behavior related to the use of windows in german households. Build- 
ing and Environment 103, 54-69.

Calì, D., T. Osterhage, and D. Müller (2011a). Rebound effect related to retrofit solutions for residential housing - monitoring data from a field test. SB11.

Calì, D., T. Osterhage, and D. Müller (2011b). Retrofit solutions for residential buildings. International Journal of Sustainable Building Technology and Urban Development 2(2), 131-136.

Calì, D., T. Osterhage, R. Streblow, and D. Müller (2016). Energy performance gap in refurbished german dwellings: Lessonlearned from a field test. Energy and buildings (127), 1-13.

Calì, D., M. T. Wesseling, and D. Müller (2018). Winprogen: A markov-chain-based stochastic window status profile generator for the simulation of realistic energy performance in buildings. Building and Environment 136, 240-258.

Dall'O', G., L. Sarto, A. Galante, and G. Pasetti (2012). Comparison between predicted and actual energy performance for winter heating in highperformance residential buildings in the lombardy region (italy). Energy and buildings 47, 247-253.

Deutsches Institut für Normung e.V. (2014). Die neue Energieeinsparverordnung: Erläuterungen, Änderungen, Rechtstexte (2., vollst. überarb. Aufl. ed.). Recht. Bauwesen. Berlin: Beuth.

DIN-EN-15242 (2007). Calculation methods for the determination of air flow rates in buildings including infiltration. DIN Deutsches Institut für Normung e. $V$..

Erbs, D. G., S. A. Klein, and J. A. Duffie (1982). Estimation of the diffuse radiation fraction for hourly, daily and monthly-average global radiation.

Fabi, V., V. A. Rune, S. Corgnati, and B. W. Olesen (2012). Occupants' window opening behaviour: A literature review of factors influencing occupant behaviour and models. Building and Environment 58, 188-198.

Fritzner, Klaus, Finke, Ulrich (2012). Lüftungsregeln für freie Lüftung. Bundesanstalt für Arbeitsschutz und Arbeitsmedizin.

Fuchs, M., A. Constantin, M. Lauster, P. Remmen, R. Streblow, and D. Müller (2015). Structuring the building performance modelica library aixlib for open collaborative development. 14th International Conference of the IBPSA.

Galvin, R. (2014). Making the 'rebound effect' more useful for performance evaluation of thermal retrofits of existing homes: Defining the 'energy savings deficit' and the 'energy performance gap'. Energy and buildings 69, 515-524.
Haas, R. and P. Biermayr (2000). The rebound effect for space heating empirical evidence from austria. Energy Policy 28(6-7), 403-410.

Haldi, F., D. Calì, R. K. Andersen, M. Wesseling, and D. Müller (2017). Modelling diversity in building occupant behaviour: A novel statistical approach. Journal of Building Performance Simulation 10(5$6), 1-18$.

Hall, M. (2004). Untersuchungen zum thermisch induzierten Luftwechselpotential von Kippfenstern. Ph.D. Thesis. University Kassel, Department of Architecture, Urban Planning and Landscape Architecture.

Menezes, A. C., A. Cripps, D. Bouchlaghem, and R. Buswell (2012). Predicted vs. actual energy performance of non-domestic buildings: Using postoccupancy evaluation data to reduce the performance gap. Applied Energy 97, 355-364.

Molitor, C., A. Benigni, A. Helmedag, K. Chen, D. Calì, A. Monti, and D. Müller (2012). Multiphysics test bed for renewable energy systems in smart homes: New york, ny / ieee. IEEE transactions on industrial electronics (60), 1235-1248.

Molitor, C., D. Calì, R. Streblow, F. Ponci, and D. Müller (2012). New energy concepts and related information technologies : Dual demand side management: Contribution to a conference proceedings. ISGT 2012 - IEEE PES Innovative Smart Grid Technologies.

Molitor, C., F. Ponci, A. Monti, D. Calì, and D. Müller (2011). Consumer benefits of electricityprice-driven heat pump operation in future smart grids. IEEE International Conference on Smart Measurements of Future Grids: SMFG 2011, Bologna, Italy.

Schnieders, J. (2003). Lüftungsstrategien für den Sommer: Ein vereinfachtes Verfahren zur Abschätzung des sommerlichen Luftwechsels. Darmstadt: Passivhaus Institut Darmstadt.

Tronchin, L. and K. Fabbri (2008). Energy performance building evaluation in mediterranean countries: Comparison between software simulations and operating rating simulation. Energy and buildings 40(7), 1176-1187.

VDI (2002). Verein Deutscher Ingenieure, VDI-Wärmeatlas: Berechnungsblätter für en Wärmeübergang (9. ed.). Springer Verlag.

Wesseling, M. (2012). Entwicklung von Simulationsmodellen für Komponenten von LowEx Gebäuden in der objektorientierten Programmiersprache Modelica. Diploma thesis, RWTH Aachen University, Aachen. 